\title{
BMJ Open Sarcopenia, physical frailty, undernutrition and obesity cooccurrence among Portuguese community-dwelling older adults: results from Nutrition UP 65 cross-sectional study
}

\author{
Ana Rita Sousa-Santos (10 , ${ }^{1}$ Cláudia Afonso, ${ }^{1,2}$ Nuno Borges, ${ }^{1,3}$ \\ Alejandro Santos, ${ }^{1,4}$ Patrícia Padrão, ${ }^{1,2}$ Pedro Moreira, ${ }^{1,2,5}$ Teresa F Amaral ${ }^{1,6}$
}

To cite: Sousa-Santos AR, Afonso C, Borges N, et al. Sarcopenia, physical frailty, undernutrition and obesity cooccurrence among Portuguese communitydwelling older adults: results from Nutrition UP 65 crosssectional study. BMJ Open 2020;10:e033661. doi:10.1136/ bmjopen-2019-033661

- Prepublication history and additional material for this paper are available online. To view these files, please visit the journal online (http://dx.doi. org/10.1136/bmjopen-2019033661).

Received 19 August 2019 Revised 23 December 2019 Accepted 21 April 2020
D) Check for updates

(c) Author(s) (or their employer(s)) 2020. Re-use permitted under CC BY-NC. No commercial re-use. See rights and permissions. Published by BMJ.

For numbered affiliations see end of article.

\section{Correspondence to} Dr Ana Rita Sousa-Santos; anaritadesousasantos@gmail. com

\section{ABSTRACT}

Objectives To investigate the coexistence of sarcopenia, frailty, undernutrition and obesity and to identify the factors associated with the cooccurrence of these conditions in an older population.

Design Cross-sectional.

Setting Portugal.

Participants 1454 older adults with 65 years or older, from Nutrition UP 65 study.

Primary and secondary outcome measures Sarcopenia was identified using the European Working Group on Sarcopenia in Older People 2 guidelines and physical frailty using Fried phenotype. Mini-Nutritional Assessment-Short Form was used to ascertain undernutrition, and obesity was evaluated by body mass index.

Results $57.3 \%$ presented at least one condition, $38.0 \%$ were identified with one and $19.3 \%$ were identified with two or more conditions. When all preconditions were considered, $95.7 \%$ of the older adults presented at least one of these preconditions or conditions. Multinomial logistic regression multivariate analysis revealed that being male (OR $0.61 ; 95 \% \mathrm{Cl} 0.43$ to 0.88 ), being married or in a common-law marriage (OR $0.58 ; 95 \% \mathrm{Cl} 0.40$ to 0.84 ) and having a higher educational level (OR 0.23; $95 \%$ $\mathrm{Cl} 0.07$ to 0.73 ) were inversely associated with having two or more conditions, while age $>75$ years (OR 1.60; $95 \% \mathrm{Cl}$ 1.14 to 2.24$)$, a poor self-perception of health status (OR $5.61 ; 95 \% \mathrm{Cl} 3.50$ to 9.01 ), $\geq 5$ medications (OR $3.11 ; 95 \%$ Cl 1.77 to 5.46) and cognitive impairment (OR 1.84; $95 \%$ Cl 1.37 to 2.48) were directly associated.

Conclusions Almost three out of five older adults presented at least one of the conditions related to nutritional status, and about one in five had two or more of these occurrences. However, the low coexistence observed between all of these reinforces the need to assess them all individually during the geriatric assessment.

\section{INTRODUCTION}

Sarcopenia, frailty, undernutrition and obesity are frequently identified in older populations. Although research on health in older adults generally focuses on the presence of
Strengths and limitations of this study

- The study of the coexistence of all four conditions (sarcopenia, physical frailty, undernutrition and obesity) in older adults is a novelty.

- This is a cross-sectional study.

- A large sample of 1454 older adults was studied.

- Body mass index was used to identify preobesity and obesity.

- Muscle mass assessment for sarcopenia diagnosis was carried out using anthropometric measures.

multiple chronic diseases, commonly termed 'multimorbidity', ' there are other relevant health conditions such as geriatric syndromes that are multifactorial conditions highly prevalent in older adults and that do not fall into discrete disease categories. ${ }^{2}$

Both sarcopenia and physical frailty include measures of muscle strength and performance to diagnose muscle dysfunction and are both associated with similar poor health outcomes. $^{34}$ Despite the similarities, sarcopenia was not found to be a useful biomarker of frailty, but its absence is a good indicator for the absence of frailty. ${ }^{5}$ In a large sample of community-dwelling older adults, sarcopenia prevalence in frail individuals ranged from $40 \%$ to $72 \%$, depending on the definition used. ${ }^{5}$ Moreover, sarcopenia and frailty were agreed to be separate conditions often associated with malnutrition. ${ }^{6}$ In fact, in a study with overweight and obese cancer patients, sarcopenia was prevalent across different levels of nutrition risk. ${ }^{7}$ In addition, the double burden of malnutrition was characterised by World Health Organization (WHO) as the coexistence of undernutrition along with overweight and obesity, namely, within individuals, but it needs to be further explored. 
Despite being distinct, these conditions share many common pathophysiological pathways ${ }^{348}$ and are associated with poor health outcomes. ${ }^{9-11}$ Even though they have been extensively studied in older adults, the majority of the previous studies focused in each individual condition. Therefore, the study of their cooccurrence and their associated factors may help identify which individuals have an increased risk of cumulative health consequences and ascertain about older adults' health status. Additionally, it may provide useful information to support the development of suitable healthcare responses. Hence, the main goals of the present study are to investigate the coexistence of sarcopenia, physical frailty, undernutrition and obesity, and to evaluate the factors associated with the cooccurrence of these conditions in a large sample of the Portuguese older population.

\section{MATERIALS AND METHODS Design and participants}

The study sample included individuals enrolled in the Nutrition UP 65 study, a cross-sectional observational study conducted in Portugal. As described in detail previously, ${ }^{12}$ a cluster sample of 1500 individuals with 65 years or older, representative of the Portuguese older population in terms of age, sex, education and regional area was selected. Individuals presenting any condition that precluded the collection of venous blood samples or urine (eg, dementia or urinary incontinence) were not included. Data were gathered between December 2015 and June 2016. A structured questionnaire was applied by interview, conducted by eight trained registered nutritionists and anthropometric data were also collected. From the initial sample, 46 individuals could not be evaluated regarding frailty status $(n=43)$ and body mass index (BMI; $n=4$ ) due to missing data and were therefore excluded from the present analysis.

\section{Measurements}

Anthropometric measurements were collected following standard procedures. ${ }^{13}$ A calibrated stadiometer (SECA 213, SECA GmbH, Hamburg, Germany) with $0.1 \mathrm{~cm}$ resolution was used to measure standing height. Body weight (in $\mathrm{kg}$ ) was measured with a calibrated portable electronic scale (SECA 803, SECA GmbH, Hamburg, Germany) with $0.1 \mathrm{~kg}$ resolution, with the participants wearing light clothes. When it was not possible to measure standing height or weigh a patient, height was obtained indirectly from non-dominant hand length, ${ }^{14}$ measured with a calibrated calliper (Fervi Equipment) with $0.1 \mathrm{~cm}$ resolution and body weight was estimated from mid-upper arm and calf circumferences. ${ }^{15}$ Mid-upper arm and calf circumferences were measured with a metal tape measure (Lufkin W606 PM, Lufkin, Sparks, Maryland, USA) with $0.1 \mathrm{~cm}$ resolution.

Handgrip strength (HGS) was measured in the nondominant hand with a calibrated Jamar Plus Digital Hand Dynamometer (Sammons Preston, Bolingbrook,
Illinois, USA). As recommended by the American Society of Hand Therapists, participants were asked to sit in a chair without arm rest, with their shoulders adducted, their elbows flexed $90^{\circ}$ and their forearms in neutral position. ${ }^{16}$ Three measurements with a 1 minute pause between them were performed by each individual and the higher value, recorded in kilogram-force (kgf), was used for the analysis. Individuals unable to perform the measurement with the non-dominant hand were asked to use the dominant hand.

Walking time was measured over a distance of $4.6 \mathrm{~m}$ in an unobstructed corridor. Individuals were instructed to walk at usual pace and walking time was recorded by a chronometer (School Electronic Stopwatch, Dive049, Topgim, Portugal), in seconds. Those unable to perform the test due to mobility or balance limitations were considered frail for this criterion $(n=28)$.

Information regarding educational level, household income, smoking status, alcohol consumption and prescription medication use was self-reported. Cognitive impairment was ascertained using the Portuguese version of the Mini-Mental State Examination. Individuals were classified as cognitive impaired using the following criteria: individuals with no education, $\leq 15$ points; $1-11$ years of school completed, $\leq 22$ points and $>11$ years of school completed, $\leq 27$ points. ${ }^{17}$

\section{Sarcopenia status}

Sarcopenia was identified using the European Working Group on Sarcopenia in Older People (EWGSOP) 2 guidelines, as the presence of low muscle strength measured by HGS, plus low muscle quantity and quality. ${ }^{4}$ Low muscle strength was classified as grip strength $<16$ $\mathrm{kgf}$ in women and $<27 \mathrm{kgf}$ in men, ${ }^{18}$ and low muscle quantity and quality was classified as calf circumference $<31$ $\mathrm{cm} .{ }^{19}$ Presarcopenia was identified by the presence of low muscle strength.

\section{Frailty status}

Physical frailty was defined according to the Fried et al frailty phenotype. ${ }^{3}$ Frailty was classified as the presence of three or more of the following five criteria: 'shrinking': evaluated by self-reported unintentional weight loss $(>4.5$ $\mathrm{kg}$ lost unintentionally in prior year); 'weakness': assessed by low HGS adjusted for gender and BMI; 'poor endurance and energy': evaluated by self-reported exhaustion using two items from the Center for Epidemiologic Studies Depression Scale ${ }^{20}$; 'slowness': identified by walking time, adjusted for gender and standing height; and 'low physical activity': assessed by the short form of the International Physical Activity Questionnaire, ${ }^{21}$ by means of kilocalories expended per week, adjusted for gender (men <383 kcal/week and women $<270 \mathrm{kcal} /$ week). Individuals with one or two of these criteria were classified as prefrail.

\section{Undernutrition status}

The Portuguese version of the Mini-Nutritional Assessment-Short Form was applied. A participant scoring $\leq 7$ 
out of 14 points was classified as undernourished, one that scores between 8 and 11 is at risk of undernutrition and one scoring between 12 and 14 points was considered well nourished. ${ }^{22}$ Due to the small number of undernourished individuals $(n=18)$, undernutrition and undernutrition risk were studied as a single category.

\section{Body mass index (BMI)}

BMI was calculated as weight $(\mathrm{kg}) /$ height $^{2}(\mathrm{~m})$ and subjects were classified as overweight for BMI between 25.0 and $29.9 \mathrm{~kg} / \mathrm{m}^{2}$ and obese for BMI of $30.0 \mathrm{~kg} / \mathrm{m}^{2}$ or above. ${ }^{11}$

\section{Statistical analysis}

Characteristics of the study sample were described as frequencies and percentages, computed separately according to the number of conditions, and $\chi^{2}$ or Fisher's exact test was applied to test differences between study groups.

Multiple imputations were carried out to handle missing data for the following variables: marital status $(n=1)$, selfperception of health status $(n=4)$ and alcohol consumption $(n=2)$. The Markov Chain Monte Carlo approach was used, with 5 imputation data sets and 10 iterations. Then, a multinomial logistic regression was conducted to quantify the association between the number of diseases or conditions (dependent variable) and independent variables. Sex, age, residential status, regional area, marital status, educational level, household income, self-perception of health status, smoking status, alcohol consumption, medication use and cognitive function were variables included in the model. Odds ratios (OR) and their respective $95 \%$ Confidence Intervals (CI) were calculated.

All statistical analyses were performed with IBM SPSS Statistics V.25 (SPSS, an IBM Company), and the statistical significance level was set at a $\mathrm{p}$ value $<0.05$.

\section{RESULTS}

In the 1454 older adults included in this study, $42.6 \%$ $(\mathrm{n}=620)$ presented none of the conditions evaluated, $38.0 \%(\mathrm{n}=553)$ were identified with one of the conditions, 225 older adults $(15.5 \%)$ were identified with two conditions, 55 individuals had three of the conditions evaluated $(3.8 \%)$ and only 1 older adult was identified with all $(0.1 \%)$. The median age of the individuals was 74 years (65-100). Comparison between included and excluded individuals revealed a higher proportion of excluded individuals from the Alentejo/Algarve and Madeira/Azores $(\mathrm{p}=0.001)$, who do not know or did not declare their income $(\mathrm{p}=0.030)$, who were non-drinkers $(p=0.005)$ and who were more likely to be cognitively impaired $(\mathrm{p}=0.017)$ (online supplementary table 1$)$. Older adults identified with multiple conditions $(\geq 2)$ were more likely to be women, more than 75 years and being single, divorced or widower $(\mathrm{p}<0.001)$ (table 1$)$. Presarcopenia and sarcopenia were diagnosed in 457 $(31.4 \%)$ and $65(4.5 \%)$ older adults, respectively, while prefrailty was identified in $791(54.4 \%)$ and frailty in 310 (21.3\%) individuals. Also $646(44.4 \%)$ were classified as overweight and $568(39.1 \%)$ were obese. Undernutrition was present in $18(1.2 \%)$ older adults and $211(14.5 \%)$ were at risk of undernutrition.

When presarcopenia, prefrailty and overweight status were also accounted for the analysis, together with sarcopenia, frailty, obesity and undernutrition status, it was observed that only $4.3 \%$ of the older adults $(n=63)$ presented none of the preconditions or conditions evaluated, and $22.6 \%$ were identified with one, $36 \%$ with two and $32.1 \%$ with three of the preconditions or conditions. All four preconditions or conditions were identified in $5 \%$ of the sample $(n=72)$ (online supplementary table 2$)$.

Figure 1 shows the distribution of each condition across the study groups. Obesity was the most frequent condition among the group with only one condition (66.5\%), followed by frailty $(14.6 \%)$ and undernutrition or undernutrition risk $(13.6 \%)$. For the group with two or more conditions, frailty was the most frequent $(81.5 \%)$, followed by obesity $(71.2 \%)$ and undernutrition or undernutrition risk in third $(54.8 \%)$. Sarcopenia was the less frequent condition among both groups, and it was identified in $5.2 \%$ of the individuals with one condition and $12.8 \%$ of the older adults with two or more conditions.

Pairwise coexistence between the conditions evaluated is presented in table 2 . The highest coexistence was observed between frailty and obesity (10.5\%). Furthermore, it was also observed that undernutrition or undernutrition risk coexisted with frailty in $7.0 \%$ and obesity in $5.9 \%$ of the sample. Sarcopenic obesity was identified in only two individuals $(0.1 \%)$.

Results of coexistences when all preconditions were included revealed a higher coexistence for prefrailty/ frailty with BMI over $25 \mathrm{~kg} / \mathrm{m}^{2}(64.2 \%)$, followed by prefrailty/frailty with presarcopenia/sarcopenia (35.9\%) and presarcopenia/sarcopenia with BMI over $25 \mathrm{~kg} /$ $\mathrm{m}^{2}(29.2 \%)$. Coexistence of undernutrition or undernutrition risk with prefrailty/frailty and pre-sarcopenia/ sarcopenia was $14.4 \%$ and $6.9 \%$, respectively. The double burden of malnutrition, characterised by the presence of undernutrition or undernutrition risk and overweight or obesity concurrently, was identified among $11.5 \%$ older adults (online supplementary table 3 ).

The results of the multinomial logistic regression analyses after multiple imputations are shown in table 3 . When the category 'none of the conditions' was used as reference variable, it was found that presenting one condition was directly associated with living in Alentejo/ Algarve (OR 1.46; 95\% CI 1.02 to 2.07), poor or very poor self-perception of health status (OR 1.64; 95\% CI 1.11 to 2.41), taking 1-4 medications (OR 1.52; 95\% CI 1.08 to 2.14) and $\geq 5$ medications (OR $1.81 ; 95 \%$ CI 1.21 to 2.70 ) and inversely associated with male gender (OR 0.74; $95 \%$ CI 0.57 to 0.96 ) and higher education (OR 0.39; $95 \%$ CI 0.20 to 0.78$)$.

Furthermore, having two or more conditions was inversely associated with male gender (OR $0.61 ; 95 \%$ CI 
Table 1 Characteristics of the participants according to the number of conditions evaluated in this study $\dagger$

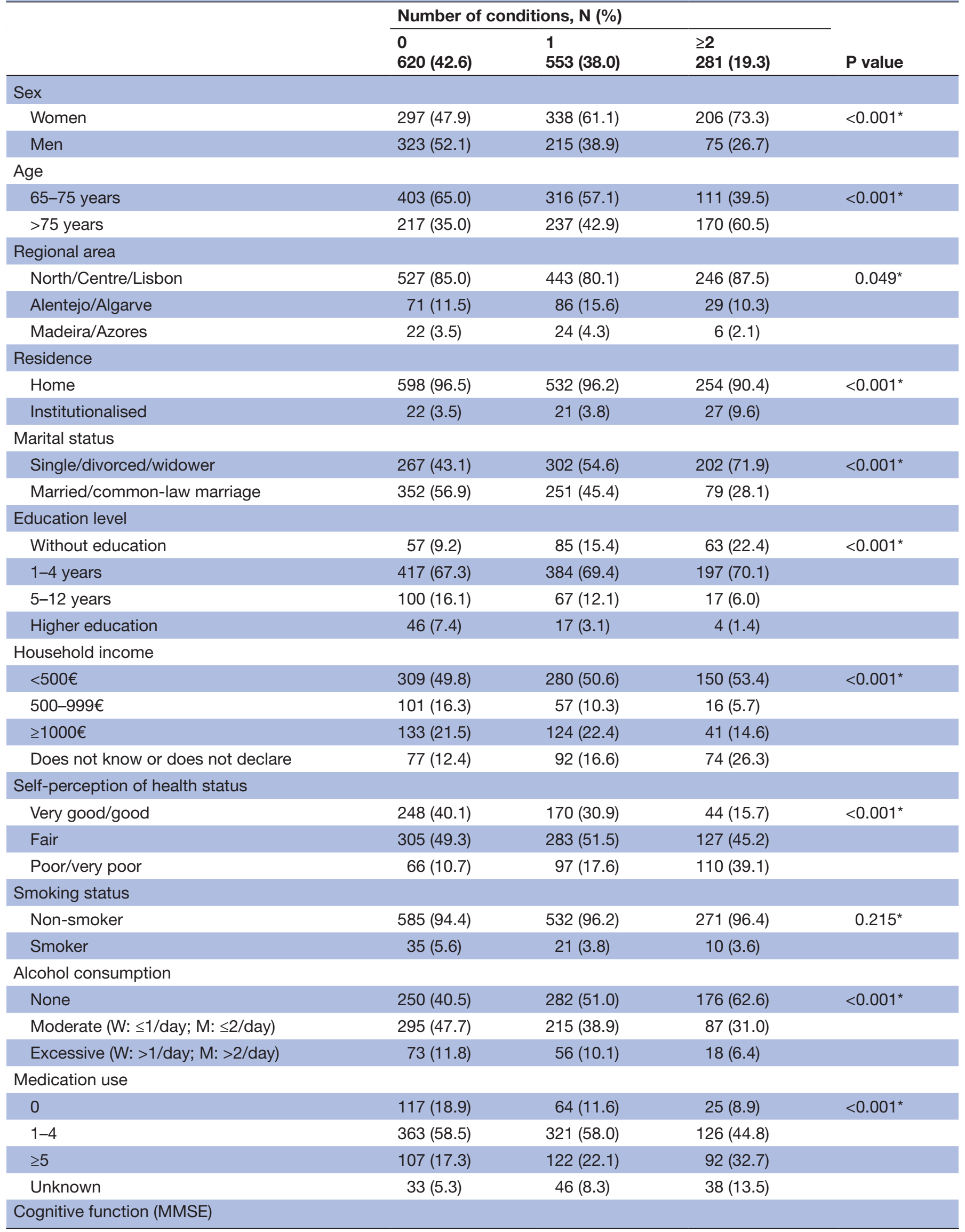




\begin{tabular}{|c|c|c|c|c|}
\hline & \multicolumn{3}{|c|}{ Number of conditions, $\mathrm{N}(\%)$} & \multirow[b]{2}{*}{$\mathbf{P}$ value } \\
\hline & $\begin{array}{l}0 \\
620(42.6)\end{array}$ & $\begin{array}{l}1 \\
553(38.0)\end{array}$ & $\begin{array}{l}\geq 2 \\
281(19.3)\end{array}$ & \\
\hline Impaired & $31(5.0)$ & $26(4.7)$ & $35(12.5)$ & \\
\hline
\end{tabular}

${ }^{*} \chi^{2}$ test.

†Percentages may not add to $100 \%$ due to rounding. Data before multiple imputations. Information was not obtained: marital status $\mathrm{n}=1$ $(0.1 \%)$; self-perception of health status $n=4(0.3 \%)$; alcohol consumption $n=2(0.1 \%)$.

M, men; MMSE, Mini-Mental State Examination; W, women.

0.43 to 0.88$)$, being married or in a common-law marriage (OR $0.58 ; 95 \%$ CI 0.40 to 0.84 ), a higher educational level (OR 0.36 ; $95 \%$ CI 0.18 to 0.72 for $5-12$ years of education; OR $0.23 ; 95 \%$ CI 0.07 to 0.73 for higher education), an household income between 500 and $999 €$ (OR 0.50; $95 \%$ CI 0.30 to 0.83 ) and directly associated with age $>75$ years (OR 1.60; 95\% CI 1.14 to 2.24), a fair (OR 1.94; $95 \%$ CI: 1.29 to 2.90$)$ and poor or very poor self-perception of health status (OR: $5.61 ; 95 \%$ CI: 3.50 to 9.01 ), medication use: $1-4$ medications (OR: $1.71 ; 95 \%$ CI 1.31 to 2.25 ), $\geq 5$ medications (OR 3.11;95\% CI 1.77 to 5.46 ) and unknown medication (OR 2.56; 95\% CI 1.80 to 3.66) and cognitive impairment (OR 1.84; 95\% CI 1.37 to 2.48) (table 3).

\section{DISCUSSION}

Within this large sample of older adults, almost three out of five presented at least one of the studied conditions, namely, sarcopenia, physical frailty, obesity and undernutrition/undernutrition risk, and about one-fifth had two or more of these conditions. However, when the preconditions state was integrated in this analysis, only a small proportion $(4.3 \%)$ of the older adults presented none

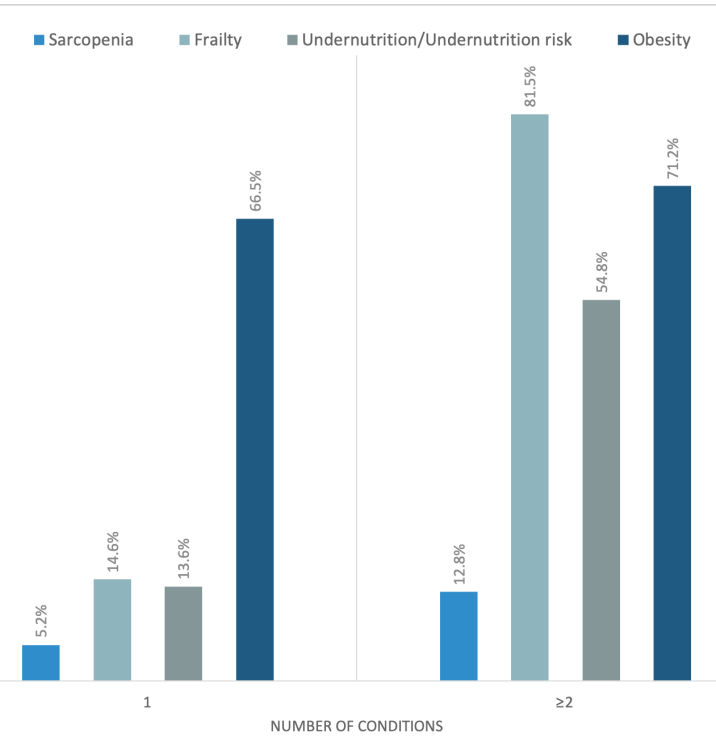

Figure 1 Frequency of sarcopenia, frailty, undernutrition or undernutrition risk and obesity according to the number of conditions. of the preconditions or conditions evaluated. Considering the distribution of these conditions among study groups, it was found that obesity was unquestionably the main contributor to the group with one condition, nevertheless, a large frequency of frailty was observed in older adults with two or more conditions. Also, the highest coexistence was observed between frailty and obesity $(10.5 \%)$, but these were also the most frequent conditions in our sample.

The prevalence of these conditions individually was previously discussed in depth. ${ }^{23-26}$ Briefly, obesity and frailty are very frequent among Portuguese older adults, ${ }^{2326}$ and lower frequencies of undernutrition and sarcopenia were observed in these individuals. ${ }^{24}{ }^{25}$ Nevertheless, the majority of the older adults had low muscle strength, the primary parameter of sarcopenia. ${ }^{25}$ An important finding of this study is that the double burden of malnutrition within individuals was found in more than one-tenth of the sample. Interestingly, when only obesity and undernutrition or undernutrition risk were accounted, coexistence was still observed in $5.9 \%$ older adults, even though BMI is part of undernutrition assessment. This indicates that despite the higher adiposity levels observed in some individuals, some may still be at risk of experiencing several health consequences of a state of undernutrition.

Frailty and obesity were simultaneously identified in a large proportion of the participants with two or more conditions. The influence of these conditions on older adults' health has been brought up and discussed by several authors. When the impact of frailty and BMI

Table 2 Cooccurrence of sarcopenia, frailty, undernutrition or undernutrition risk and obesity

\begin{tabular}{llll}
\hline & N (\%) & & \\
\cline { 2 - 4 } & Sarcopenia & $\begin{array}{l}\text { Physical } \\
\text { frailty }\end{array}$ & $\begin{array}{l}\text { Undernutrition/ } \\
\text { undernutrition } \\
\text { risk }\end{array}$ \\
\hline $\begin{array}{l}\text { Sarcopenia } \\
\text { Physical frailty }\end{array}$ & $32(2.2)$ & & \\
$\begin{array}{l}\text { Undernutrition/ } \\
\text { undernutrition risk }\end{array}$ & $22(1.5)$ & $102(7.0)$ & \\
Obesity & $2(0.1)$ & $152(10.5)$ & $86(5.9)$ \\
\hline
\end{tabular}


Table 3 Results from the multinomial logistic regression analysis, regarding the number of conditions. Reference category: none condition identified

\begin{tabular}{|c|c|c|c|c|}
\hline & \multicolumn{4}{|c|}{ Number of conditions } \\
\hline & \multicolumn{2}{|l|}{1} & \multicolumn{2}{|l|}{$\geq 2$} \\
\hline & OR $(95 \% \mathrm{Cl})$ & $P$ value & OR $(95 \% \mathrm{Cl})$ & $P$ value \\
\hline \multicolumn{5}{|l|}{ Sex } \\
\hline Women & 1.00 & & 1.00 & \\
\hline Men & $0.74(0.57$ to 0.96$)$ & 0.024 & $0.61(0.43$ to 0.88$)$ & 0.009 \\
\hline \multicolumn{5}{|l|}{ Age } \\
\hline $65-75$ years & 1.00 & & 1.00 & \\
\hline$>75$ years & 1.10 (0.84 to 1.43$)$ & 0.483 & 1.60 (1.14 to 2.24$)$ & 0.007 \\
\hline \multicolumn{5}{|l|}{ Regional area } \\
\hline North/Centre/Lisbon & 1.00 & & 1.00 & \\
\hline Alentejo/Algarve & $1.46(1.02$ to 2.07$)$ & 0.039 & 0.88 (0.55 to 1.42$)$ & 0.629 \\
\hline Madeira/Azores & 1.21 (0.88 to 1.65$)$ & 0.555 & 0.50 (0.30 to 0.84$)$ & 0.179 \\
\hline \multicolumn{5}{|l|}{ Residence } \\
\hline Home & 1.00 & & 1.00 & \\
\hline Institutionalised & 0.94 (0.49 to 1.77$)$ & 0.838 & 1.47 (0.76 to 2.84$)$ & 0.261 \\
\hline \multicolumn{5}{|l|}{ Marital status } \\
\hline Single/divorced/widower & 1.00 & & 1.00 & \\
\hline Married/common-law marriage & 0.77 (0.58 to 1.00$)$ & 0.050 & $0.58(0.40$ to 0.84$)$ & 0.003 \\
\hline \multicolumn{5}{|l|}{ Education level } \\
\hline Without education & 1.00 & & 1.00 & \\
\hline $1-4$ years & 0.77 (0.52 to 1.12$)$ & 0.173 & $0.74(0.47$ to 1.15$)$ & 0.176 \\
\hline $5-12$ years & 0.65 (0.40 to 1.06$)$ & 0.082 & 0.36 (0.18 to 0.72$)$ & 0.004 \\
\hline Higher education & 0.39 (0.20 to 0.78$)$ & 0.008 & $0.23(0.07$ to 0.73$)$ & 0.014 \\
\hline \multicolumn{5}{|l|}{ Household income } \\
\hline$<500 €$ & 1.00 & & 1.00 & \\
\hline $500-999 €$ & 0.97 (0.65 to 1.45$)$ & 0.865 & $0.50(0.30$ to 0.83$)$ & 0.008 \\
\hline$\geq 1000 €$ & 0.80 (0.49 to 1.30$)$ & 0.361 & $0.56(0.28$ to 1.13$)$ & 0.103 \\
\hline Does not know or does not declare & 0.91 (0.63 to 1.31$)$ & 0.619 & 0.72 (0.47 to 1.10$)$ & 0.124 \\
\hline \multicolumn{5}{|l|}{ Self-perception of health status } \\
\hline Very good/good & 1.00 & & 1.00 & \\
\hline Fair & $1.18(0.90$ to 1.53$)$ & 0.227 & 1.94 (1.29 to 2.90$)$ & 0.001 \\
\hline Poor/very poor & $1.64(1.11$ to 2.41$)$ & 0.012 & 5.61 (3.50 to 9.01$)$ & $<0.001$ \\
\hline \multicolumn{5}{|l|}{ Smoking status } \\
\hline Non-smoker & 1.00 & & 1.00 & \\
\hline Smoker & 0.87 (0.65 to 1.17$)$ & 0.635 & 1.06 (0.69 to 1.60$)$ & 0.899 \\
\hline \multicolumn{5}{|l|}{ Alcohol consumption } \\
\hline None & 1.00 & & 1.00 & \\
\hline Moderate (W: $\leq 1 /$ day; M: $\leq 2 /$ day) & 0.85 (0.65 to 1.11$)$ & 0.233 & 0.77 (0.54 to 1.10$)$ & 0.147 \\
\hline Excessive (W: >1/day; $M:>2 /$ day) & 0.91 (0.60 to 1.39$)$ & 0.674 & $0.68(0.36$ to 1.26$)$ & 0.219 \\
\hline \multicolumn{5}{|l|}{ Medication use } \\
\hline 0 & 1.00 & & 1.00 & \\
\hline $1-4$ & 1.52 (1.08 to 2.14$)$ & 0.020 & 1.71 (1.31 to 2.25$)$ & 0.047 \\
\hline$\geq 5$ & 1.81 (1.21 to 2.70$)$ & 0.005 & 3.11 (1.77 to 5.46$)$ & $<0.001$ \\
\hline Unknown & $1.66(0.95$ to 2.91$)$ & 0.079 & 2.56 (1.80 to 3.66$)$ & 0.008 \\
\hline
\end{tabular}




\begin{tabular}{|c|c|c|c|c|}
\hline & \multicolumn{4}{|c|}{ Number of conditions } \\
\hline & \multicolumn{2}{|l|}{1} & \multicolumn{2}{|l|}{$\geq 2$} \\
\hline & OR (95\% Cl) & $P$ value & OR (95\% Cl) & $P$ value \\
\hline Not impaired & 1.00 & & 1.00 & \\
\hline Impaired & 0.83 (0.47 to 1.47$)$ & 0.521 & 1.84 (1.37 to 2.48$)$ & 0.040 \\
\hline
\end{tabular}

Bold text indicates a statistically significant difference with a p-value less than 0.05 .

M, men; MMSE, Mini-Mental State Examination; W, women.

on mortality was evaluated, it was found that frail older adults who were obese had a significantly higher mortality risk. ${ }^{27}$ Also, it was observed that in older people who were normal weight or underweight, higher levels of frailty were associated with poorer survival. ${ }^{27}$ Additionally, weight loss and exercise interventions had been pointed as beneficial among overweight or obese older adults, namely in the improvement of physical function and biomarkers of physical dysfunction. ${ }^{28}{ }^{29}$ Regardless of the evidence presented, weight loss in older adults must be taken with caution, because it can also result in losses of lean body mass and bone mineral density. ${ }^{29}$ At the other end of the spectrum, physical frailty and undernutrition/undernutrition risk coexistence were lower to the one observed for frailty and obesity. Results of a meta-analysis conducted by Verlaan et al revealed that older adults were likely to be physically frail, but only a small percentage of the physically frail older people in the community was identified as undernourished. ${ }^{30}$ In the present study, $44.5 \%$ of the undernourished or at undernutrition risk individuals were frail, and $32.9 \%$ of the individuals who were frail were also undernourished or at undernutrition risk. However, in agreement with the previous results, ${ }^{30}$ when undernourished individuals were considered separately from those who were at nutritional risk, it was observed that $72.2 \%$ of the undernourished individuals were frail, while only $4.2 \%$ of frail older adults were undernourished. Nevertheless, it is still important to acknowledge the small number of undernourished older adults identified in this study $(\mathrm{n}=18)$.

Sarcopenia and physical frailty are not identical, but they share similar criteria and a close relationship between the two is often pointed out in the literature. Actually, overlap between sarcopenia and frailty is discussed in both EWGSOP consensus, suggesting that most frail people exhibit sarcopenia, and some older people with sarcopenia are also frail. ${ }^{48}$ Our data showed a low coexistence between them $(2.2 \%)$, which is in line with previous results that observed a low coexistence of sarcopenia and frailty even when various definitions were used. ${ }^{31}$ This supports the fact that sarcopenia and frailty are still two distinct conditions. Indeed, in the recent EWGSOP consensus sarcopenia is described as a contributor to the development of physical frailty, while frailty syndrome represents a much broader concept. ${ }^{4}$ However, it is worth mentioning that the methodologic differences often observed between the studies raise the difficulty to draw conclusions. It was also interesting to find that when presarcopenia and prefrailty were also considered, they cooccurred in only $35.9 \%$ individuals, even though they share similar diagnostic measures. In fact, the difference in HGS cutoff points for sarcopenia and frailty diagnosis $^{34}$ is a major contributor to this low coexistence, as only $35.8 \%$ older adults had simultaneously the low HGS criterion for both conditions (data not shown). Sarcopenia and undernutrition coexistence was previously discussed. ${ }^{25}$

Although, according to our knowledge, the study of coexistence of all these conditions is lacking. A recent cross-sectional study in 100 patients revealed a higher overlap between three of these conditions (sarcopenia, frailty and undernutrition), however this study was developed in hospital setting, and higher frequencies of each condition were observed among these older adults. ${ }^{32}$

When factors associated with presenting several of these conditions were examined through multinomial regression analyses, being male, married or in common-law marriage and having attended 5 or more years to school were inversely associated with two or more of the studied conditions evaluated here. In the present study, all the studied conditions sarcopenia, frailty, undernutrition/ undernutrition risk and obesity were more frequent among women.

As expected, age was positively associated with presenting more than one condition, since the aetiology of most of these conditions is closely related with the ageing process. ${ }^{348}$ Moreover, a fair, and especially a poor or very poor self-perception of health status were positively linked with presenting multiple conditions. The decline in physical function commonly observed in older people suffering from these conditions may partially explain this, as it may influence individuals' perception of their health.

Medication usage was also associated with presenting one and two or more of the conditions evaluated. Furthermore, higher odds were observed for those with a higher medication use $(\geq 5)$ and for the group with more than one condition. This reveals a state of vulnerability, as individuals with higher medication use were also more likely to refer two or more chronic diseases and, consequently, 
have poorer health status. This is in accordance with previous literature, which reported that those on more medication were more likely to be older and have worse health status. ${ }^{33}$ Regarding cognitive impairment, a significant association was observed only with the group with two or more conditions identified. Although these conditions were not individually associated with a deterioration in cognitive status (data not shown), the cumulative effect of their cooccurrence, may have had an impact on this association.

In addition, the higher cooccurrence observed when the intermediate states of these conditions were considered is in line with current evidence that indicates that some of these conditions may contribute to the development of the other conditions or diseases. This emphasises the need to evaluate all of them separately, at early stages, during the geriatric assessment. Hence, besides the use of screening tools for undernutrition and obesity, it would be relevant to also routinely screen for frailty and sarcopenia.

Some study limitations can be enumerated. First, it should be noted that the cross-sectional nature of this study does not allow us to infer about causal relationships. Second, comparison between included and excluded individuals revealed statistically significant differences for some variables, hence generalisation of the present results should be made with caution. Furthermore, muscle mass assessment for sarcopenia diagnosis was carried out using anthropometric measures, which is not the reference method to estimate muscle quality and quantity. In addition, the appropriateness of the use of BMI to estimate excessive adiposity in older adults has been questioned in the literature. ${ }^{34}$ Also, it would be of special interest to evaluate the outcomes of the cooccurrence of these conditions, namely, the extent of health consequences resulting from their cumulative effects. However, to our knowledge, this is the first study to analyse the coexistence of sarcopenia, frailty, undernutrition and obesity in older adults and to identify the factors associated with them.

The study of sarcopenia, physical frailty, undernutrition and obesity in the same sample of older adults is a novelty, and the low coexistence observed between the conditions evaluated, reinforces the need to assess them all individually during geriatric assessment. It also raises the question of how the presence of one of these conditions may mask or aggravate the state of others. Therefore, it would be important to carefully address their cumulative effects in older adults' health status and quality of life, in a near future.

\section{Author affiliations}

${ }^{1}$ FCNAUP - Faculdade de Ciências da Nutrição e Alimentação, Universidade do Porto, Porto, Portugal

${ }^{2}$ EPIUnit - Instituto de Saúde Pública, Universidade do Porto, Porto, Portugal ${ }^{3}$ CINTESIS - Centro de Investigação em Tecnologia e Serviços de Saúde, Porto, Portugal

${ }^{4}$ I3S - Instituto de Investigação e Inovação em Saúde, Universidade do Porto, Porto, Portugal
${ }^{5}$ CIAFEL - Centro de Investigação em Atividade Física, Saúde e Lazer, Universidade do Porto, Porto, Portugal

${ }^{6}$ UISPA, LAETA-INEGI - Faculdade de Engenharia, Universidade do Porto, Porto, Portugal

\section{Twitter Pedro Moreira @pedromoreiraanh}

Contributors ARSS and TFA designed this research and analysed all data. ARSS, $\mathrm{CA}, \mathrm{NB}, \mathrm{AS}, \mathrm{PP}, \mathrm{PM}$ and TFA contributed to manuscript preparation and approved the final version of the manuscript submitted for publication.

Funding The present project was $85 \%$ funded by the Public Health Initiatives Programme (PT06), financed by EEA Grants Financial Mechanism 2009-2014 and 15\% funded by Faculdade de Ciências da Nutrição e Alimentação da Universidade do Porto. Also, Ana Rita Sousa-Santos as a PhD student received a scholarship from FCT—Fundação para a Ciência e a Tecnologia, financing programme POCHPrograma Operacional Capital Humano, under the project (SFRH/BD/138362/2018).

Competing interests None declared.

Patient and public involvement Patients and/or the public were not involved in the design, or conduct, or reporting, or dissemination plans of this research.

Patient consent for publication Not required.

Ethics approval This research was conducted according to the guidelines established by the Declaration of Helsinki, and the study protocol was approved by the Ethics Committee of the department of 'Ciências Sociais e Saúde' (Social Sciences and Health) from the 'Faculdade de Medicina da Universidade do Porto' (PCEDCSS-FMUP 15/2015) and by the Portuguese National Commission of Data Protection (9427/2015). All study participants signed an informed consent form.

Provenance and peer review Not commissioned; externally peer reviewed. Data availability statement Data are available upon reasonable request.

Open access This is an open access article distributed in accordance with the Creative Commons Attribution Non Commercial (CC BY-NC 4.0) license, which permits others to distribute, remix, adapt, build upon this work non-commercially, and license their derivative works on different terms, provided the original work is properly cited, appropriate credit is given, any changes made indicated, and the use is non-commercial. See: http://creativecommons.org/licenses/by-nc/4.0/.

ORCID iD

Ana Rita Sousa-Santos http://orcid.org/0000-0001-6440-4870

\section{REFERENCES}

1 Fortin M, Lapointe L, Hudon C, et al. Multimorbidity is common to family practice: is it commonly researched? Can Fam Physician 2005;51:244-5.

2 Inouye SK, Studenski S, Tinetti ME, et al. Geriatric syndromes: clinical, research, and policy implications of a core geriatric concept. J Am Geriatr Soc 2007;55:780-91.

3 Fried LP, Tangen CM, Walston J, et al. Frailty in older adults: evidence for a phenotype. J Gerontol A Biol Sci Med Sci 2001;56:M146-57.

4 Cruz-Jentoft AJ, Bahat G, Bauer J, et al. Sarcopenia: revised European consensus on definition and diagnosis. Age Ageing 2019;48:16-31.

5 Davies B, García F, Ara I, et al. Relationship between sarcopenia and frailty in the Toledo study of healthy aging: a population based crosssectional study. J Am Med Dir Assoc 2018;19:282-6.

6 Cederholm T, Barazzoni R, Austin P, et al. ESPEN guidelines on definitions and terminology of clinical nutrition. Clin Nutr 2017;36:49-64

7 Martin L, Gioulbasanis I, Senesse P, et al. Cancer-Associated malnutrition and CT-Defined sarcopenia and Myosteatosis are endemic in overweight and obese patients. JPEN J Parenter Enteral Nutr 2020;44:227-238.

8 Cruz-Jentoft AJ, Baeyens JP, Bauer JM, et al. Sarcopenia: European consensus on definition and diagnosis: report of the European Working group on sarcopenia in older people. Age Ageing 2010;39:412-23.

9 Margetts BM, Thompson RL, Elia M, et al. Prevalence of risk of undernutrition is associated with poor health status in older people in the UK. Eur J Clin Nutr 2003;57:69-74.

10 Gentile S, Lacroix O, Durand AC, et al. Malnutrition: a highly predictive risk factor of short-term mortality in elderly presenting to the emergency department. J Nutr Health Aging 2013;17:290-4. 
11 World Health Organization (WHO). Obesity: preventing and managing the global epidemic. Report of a who consultation. World Health Organization technical report series, 2000: 894.

12 Amaral TF, Santos A, Guerra RS, et al. Nutritional strategies facing an older demographic: the nutrition up 65 study protocol. JMIR Res Protoc 2016;5:e184.

13 Stewart A, Marfell-Jones M. International Society for advancement of Kinanthropometry. International standards for anthropometric assessment. International Society for the Advancement of Kinanthropometry 2011:115.

14 Guerra RS, Fonseca I, Pichel F, et al. Hand length as an alternative measurement of height. Eur J Clin Nutr 2014;68:229-33.

15 Chumlea WC, Guo S, Roche AF, et al. Prediction of body weight for the nonambulatory elderly from anthropometry. J Am Diet Assoc 1988;88:564-8.

16 Fess EE. Clinical assessment recommendations. 2nd edn. Chicago, 1992: 41-4.

17 Guerreiro M. Testes de rastreio de defeito cognitivo e demência: Uma perspectiva prática. Rev Port Med Geral e Fam 2010;26.

18 Dodds RM, Syddall HE, Cooper R, et al. Grip strength across the life course: normative data from twelve British studies. PLoS One 2014;9:e113637.

19 Landi F, Onder G, Russo A, et al. Calf circumference, frailty and physical performance among older adults living in the community. Clin Nutr 2014;33:539-44.

20 Radloff LS. The CES-D scale. Appl Psychol Meas 1977;1:385-401.

21 Craig C, Marshall A, Sjöström M, et al. International physical activity questionnaire: 12-Country reliability and validity. Medicine \& Science in Sports \& Exercise 2003;35:1381-95.

22 Nestle Nutrition Institute. MNA Mini Nutritional Assessment, 2009. Available: http://www.mna-elderly.com/forms/mini/mna_mini portuguese.pdf

23 Sousa-Santos AR, Afonso C, Moreira P, et al. Weakness: the most frequent criterion among pre-frail and frail older Portuguese. Arch Gerontol Geriatr 2018;74:162-8.
24 Sousa-Santos AR, Afonso C, Borges N, et al. Sarcopenia and undernutrition among Portuguese older adults: results from nutrition up 65 study. Food Nutr Bull 2018;39:487-92.

25 Sousa-Santos AR, Afonso C, Borges N, et al. Factors associated with sarcopenia and undernutrition in older adults. Nutr Diet 2019.

26 Sousa-Santos AR, Afonso C, Santos A, et al. The association between $25(\mathrm{OH}) \mathrm{D}$ levels, frailty status and obesity indices in older adults. PLoS One 2018;13:e0198650.

27 Lee Y, Kim J, Han ES, et al. Frailty and body mass index as predictors of 3-year mortality in older adults living in the community. Gerontology 2014;60:475-82.

28 Porter Starr KN, McDonald SR, Bales CW. Obesity and physical frailty in older adults: a scoping review of lifestyle intervention trials. $J$ Am Med Dir Assoc 2014;15:240-50.

29 Waters DL, Ward AL, Villareal DT. Weight loss in obese adults 65years and older: a review of the controversy. Exp Gerontol 2013;48:1054-61.

30 Verlaan S, Ligthart-Melis GC, Wijers SLJ, et al. High prevalence of physical frailty among community-dwelling malnourished older Adults-A systematic review and meta-analysis. J Am Med Dir Assoc 2017;18:374-82.

31 Reijnierse EM, Trappenburg MC, Blauw GJ, et al. Common ground? The concordance of sarcopenia and frailty definitions. J Am Med Dir Assoc 2016;17:371.e7-371.e12.

32 Gingrich A, Volkert D, Kiesswetter E, et al. Prevalence and overlap of sarcopenia, frailty, cachexia and malnutrition in older medical inpatients. BMC Geriatr 2019;19:120.

33 Charlesworth CJ, Smit E, Lee DSH, et al. Polypharmacy among adults aged 65 years and older in the United States: 1988-2010. J Gerontol A Biol Sci Med Sci 2015;70:989-95.

34 Batsis JA, Mackenzie TA, Bartels SJ, et al. Diagnostic accuracy of body mass index to identify obesity in older adults: NHANES 19992004. Int J Obes 2016;40:761-7. 